\title{
Protein supply from rice in seven rice-consuming countries in Sub-Saharan Africa
}

\author{
A. Nishide ${ }^{1}$ and S. Shiratori ${ }^{2}$ \\ ${ }^{1}$ User Life Science Co. Ltd. Japan and \\ ${ }^{2}$ Research Strategy Office, Japan International Research Center for Agricultural Sciences (JIRCAS), Japan
}

In Africa, almost $70 \%$ of the protein supply comes from cereals and roots ${ }^{(1)}$. High ratio of protein supply from plant-based foods could lead to the supply of unbalanced essential amino acids, so we need to know not only the amount, but also the quality of protein supply. Among many kinds of staple foods in Sub-Saharan Africa, rice is one of the most popular staple foods in some countries and in fact the demand for rice has been rapidly increasing in this area. Our previous study showed that some nutrients were not sufficiently supplied in Madagascar, where their diets mainly rely on staple food: rice ${ }^{(2)}$. The aim of this study is to compare the ratios of protein supply from rice among seven Sub-Saharan African countries, where predominate staple is rice, and to see their changes over time.

We selected seven rice-consuming countries in Sub-Saharan Africa; Madagascar, Cote-d'lvoire, Gambia, Guinea, Guinea-Bissau, Liberia, and Senegal. Their food supply data from 1961 to 2010 were obtained from the Food Balance Sheet (FBS) of the Food and Agriculture Organization (FAO). Data of protein supply from all food and rice, per capita per day, were downloaded from the FBS. Then, we calculated the ratio of rice-derived protein supply by dividing protein supply amount from rice by that in total. We employed repeated ANOVA followed by linear trend analysis to assess the differences and the trend of the ratio of rice to protein supply among these seven countries and the five periods; 1960s, 1970s, 1980s, 1990s, and 2000s. Significance level was set at p $=0.05$.

The ratios of rice in the protein source in 2000 s were about $20-50 \%$. While Cote d'lvoire, Gambia, and Senegal were lower, Madagascar and Guinea-Bissau were higher.

When we see the changes during the five periods, the tendency of increase was detected but not significant as a trend $(\mathrm{p}=0.095)$. The interaction of country and period in ratio of protein supply from rice was observed $(\mathrm{p}<0.001)$, which implied the chronological changes differed by countries.

Significant increases in these ratios during the five periods were found for the five countries; Cote-d'lvoire $(p<0.001)$, Guinea $(p<$ $0.001)$, Guinea-Bissau $(p<0.001)$, Liberia $(p=0.023)$, and Senegal $(p=0.006)$. On the other hand, significant reduction was observed in Gambia $(p=0.016)$ and no significant but slightly upward trend was recognised in Madagascar $(p=0.070)$.

This study showed the difference in the change in ratios of protein supply from rice over time among the seven countries in Sub-Saharan Africa, where staple predominate is rice. Most countries except Gambia showed upward trend in protein supply ratio from rice. Little change was observed in Madagascar, where the protein supply highly depends on rice. We should be aware of the protein quality in these countries for nutritional improvement.

1. Ghosh (2013) Food Nutr Bull, 34, 2

2. Shiratori and Nishide (2018) Proc Nutr Soc 77, OEC3, E70. 